\title{
Las imágenes de Rayuela
}

Costiene José Durand ${ }^{1}$ que la clave de la manera de escribir de CorD tázar se encuentra en el jazz:

Each story is a sort of jam session, though adhering to a plan for artistic creation composed of fixed and stable forms. As in the case of the traditional impromptu jazz solo, it takes off from a given theme, and how it develops depends on previous knowledge and technique... A great store of already known technical procedures is at hand, some of them very complex and elaborate. So there is a richness one can count on in advance, plus personal skill in the art of improvisation, plus a subject to be developed, all of which come into action at the creative moment. (p. 42 )

En la novela Rayuela ${ }^{2}$ podríamos encontrar muchos ejemplos del riff del jazz, y los procedimientos del autor sí son complejos y ricos. Sin embargo, la complejidad misma de la obrd impide indicar un procedimiento como fuente o clave. Al leerla, nos damos cuenta de que hay varios propósitos, literarios así como filosóficos. Entre los propósitos literarios, el que sobresale es el deseo de reformar la novela, de cambiarla radicalmente. Este pasaje parece indicar el intento general del autor:

Una narrativa que no sea pretexto para la trasmisión de un "mensaje" (no hay mensaje, hay mensajeros y eso es el mensaje, así como el amor es el que ama); una narrativa que actúe como coagulante de vivencias, como catalizadora de nociones confusas y mal entendidas, y que incida en primer término en el que la escribe, para

1 En "Julio Cortázar: Storytelling Giant", Américas, eneto de 1963, pp. 39.43.

2 Todas las citas son de la edición de la Editorial Sudamericana, Buenos Aites, 1965. 
lo cual hay que escribirla como antinovela porque todo orden cerrado dejará sistemáticamente afuera esos anuncios que pueden volvernos mensajeros, acercarnos a nuestros propios límites de los que tan lejos estamos cara a cara. (p. 453):

Al escribir la antinovela, Cortázar busca (como lo buscó Octavio Paz) restaurar a la palabra su fuerza original. Pero no puede hacerlo sin antes atacar la palabra, casi aniquilarla, para después imponerle su significado y belleza originales. Lo expresa así:

Tanta palabra para lavarse de otras palabras, tanta suciedad para dejar de oler a Piver, a Caron, a Carven, a d.J.C. Quizá haya que pasar por todo eso para recobrar un derecho perdido, el uso original de la palabra. (p. 540)

El propósito del autor no es completamente negativo: en el proceso de renovar el lenguaje se aprovecha de una variedad de técnicas, con frecuencia basadas en la imagen y su uso. En la novela se describe el arte moderno como retorno a la Edad Media, la cual "había entendido el arte como una serie de imágenes, sustituidas durante el Renacimiento y la época moderna por la representación de la realidad" (p. 544). Es este aspecto de la obra - la forma y el uso de la imagen, tan importante en la Edad Media y en la novela de Cortázar- el que pensamos examinar en el presente estudio.

\section{LA FORMA DE LA IMAGEN}

La riqueza de la prosa de Cortázar consiste en gran parte en saber utilizar tantas maneras de expresarse. A continuación se mencionan algunas de las técnicas y formas de la imagen que se encuentran con más frecuencia en Rayuela.

\section{Impresionismo, expresionismo}

Se podrían citar muchos ejemplos de trozos impresionistas o expresionistas en la novela. Sólo presentaré dos de cada uno, para dar una idea de su uso por nuestro autor.

El siguiente trozo es notable no sólo por la técnica impresionista, sino también por el uso de metáforas que convierten la prosa en poesía: 
... todas las peceras al sol, y como suspendidos en el aire cientos de peces rosa y negro, pájaros quietos en su aire redondo... están las peceras bajo el sol con sus cubos, sus esferas de agua que el sol mezcla con el aire, y los pájaros rosa y negro giran danzando dulcemente en una pequeña porción de aire, lentos pájaros fríos. Los mirábamos, jugando a acercar los ojos al vidrio, pegando la nariz, encolerizando a las viejas vendedoras armadas de redes de cazar mariposas acuáticas... (p. 49).

A la metáfora básica ("pájaros quietos en su aire redondo") se añaden otras cuando Oliveira y la Maga buscan otras analogías para describir los peces: "Y' ese pez era perfectamente Giotto, te acordás, y esos dos jugaban como perros de jade, o un pez era la exacta sombra de una nube violeta" (p. 50).

$A$ veces una breve frase impresionista (interesante en este caso por la forma adverbial nada común) puede ser humorística: "Ronald se apoyó contra la puerta. Pelirrojamente en camisa a cuadros" (p. 54).

Se utiliza la técnica expresionista para expresar emociones. Traveler revela su actitud hacia Oliveira y da a conocer las emociones inspiradas en él por su amigo cuando le dice a Talita que cuando Oliveira "se junta con nosotros hay paredes que se caen, montones de cosas que se van al quinto demonio, y de golpe el cielo se pone fabulosamente hermoso, las estrellas se meten en esa panera, uno podría pelarlas y comérselas, ese pato es propiamente el cisne de Lohengrin ..." (p. 3I8). Talita también utiliza una imagen expresionista para expresar el peligro que siente alrededor de ellos:

...tengo la impresión de que estamos criando arañas o ciempiés. Las cuidamos, las atendemos, y van creciendo, al principio eran unos bichitos de nada, casi lindos, con tantas patas, y de golpe han crecido, te saltan a la cara. (p. 323).

\section{La meiáfora}

Las metáforas pueden tener valor descriptivo, describir lo filosófico, lo caótico o lo insignificante, servir de símbolo de lo insano (lo cual puede ser el fin de una búsqueda, el kibbutz del deseo).

Se notará el valor descriptivo en las siguientes frases: 
... la tapioca de la madrugada empezando a pegarse a la clarabaya... (P. gI).

Las ventanas son los ojos de la ciudad.. y naturalmente deforman todo lo que miran (p. 288).

... el silencio que había en toda música verdadera se desarrimaba lentamente de las paredes, salía de debajo del diván, se despegaba como labios o capullos. (p. 68).

En la última, el silencio llega a tener una cualidad plástica; lo inanimado - -el silencio de la música-cobra forma tangible, real, y entendemos la imagen perfectamente, a pesar del conflicto implícito en la metáfora.

También se anima lo inanimado en otro trozo, ahora para producir una emoción de terror, casi de locura. Oliveira supersticiosamente busca un terrón de azúcar que ha caído al suelo, entre los zapatos de la gente sentada alrededor de la mesa:

Lo primero que hice fue darme cuenta de que el terrón no estaba a la vista y eso que lo había visto saltar hasta los zapatos (que se movían inquietos como gallinas) ... El mozo se tiró del otro lado de la mesa, y ya éramos dos cuadtúpedos moviéndonos entre los zapatos-gallina que allá arriba empezaban a cacarear como locas... empecé a agarrar los zapatos de las mujeres y a mirar si debajo del arco de la suela no estaría agazapado el azúcar, y las gallinas cacareaban, los gallos gerentes me picoteaban el lomo, oía las carcajadas de Ronald y de Etienne... (pp. 22-23).

Así la metáfora inicial se ha aumentado' al final hasta incluir no sólo los zapatos sino también sus dueños.

Se describe la importancia de la risa para establecer la fraternidad del hombre en esta imagen: ". . la risa ella sola ha cavado más túneles útiles que todas las lágrimas de la tierra..." (p. 434). Y se simboliza el vínculo entre el hombre y su "realidad histórica" así: "A todo el mundo le pasa igual, la estatua de Jano es un despilfarro inútil, en realidad después de los cuarenta años la verdadera cara la tenemos en la nuca, mirando desesperadamente para atrás..." (p. II2).

Oliveira describe al mundo caótico de la Maga: "... un mundo donde te movías como un caballo de ajedrez que se moviera como una torre que se moviera como un alfil." (p. I8). Este caos, que se expresa 
de muchas maneras, puede conducir a la idiotez o a la locura. Morelli usa "insano" o "idiota" como símbolo o metáfora de lo que no entendemos, de lo que no podemos formular con palabras, pero que existe en nosotros (p. 417). Cortázar nos representa la locura como fenómeno visible cuando hace que el I8 repita la misma acción una y otra vez, acción siempre descrita por la misma frase, que llega a tener valor metafórico: ". . . entornó sus ojos verdes de una hermosuta maligna". (Esta frase que se encuentra por ptimera veź en la página 380 , se repite en las páginas $38 \mathrm{I}, 384 \mathrm{y}$-dos veces-en la página 385 ).

Los dibujos de tiza de colores funcionan como símbolo de lo efímero: todo es tiza, todo se borra.

La rue Dauphine de tiza gris, la escalera aplicadamente tizas pardas. la habitación con sus líneas de fuga astutamente tendidas con tiza verde claro, las cortinas de tiza blanca, la cama con su poncho donde todas las tizas ¡viva México!, el amor, sus tizas hambrientas de un fijador que las clavara en el presente, amor de tiza perfumada, boca de tiza naranja, tristeza y hartura de tizas sin color girando en un polvo imperceptible, posándose en las caras dormidas, en la tiza agobiada de los cuerpos. (p. 240)

El símbolo de las tizas del amor "hambrientas de un fijador que las, clavara en el presente", parece ofrecer una posible explicación del episodio del capítulo $4^{\mathrm{I}}$, en el que Oliveira endereza clavos. La acción parece tener valor metafórico. Como dice Oliveira en el mismo capítulo, "hay imágenes que copian todos tus movimientos. Yo soy muy sensible a esas idioteces..." (p. 298).

\section{El simil}

Los símiles de Rayuela pueden tener un valor descriptivo:

(el paraguas)

...se hundió como un barco que sucumbe al agua verde, al agua verde y procelosa... Y quedó entre el pasto, mínimo y negro, como un insecto pisoteado. (p. x6).

... viendo pasar una pinaza color borravino, hermosísima como una gran cucaracha teluciente de limpieza... (p. I7) 
... un mate es como un punto y aparte. Uno lo toma y después se puede empezar un nuevo párrafo. (p. I75)

... como de un globo de chewing-gum enorme y obsceno empieza

a asomar la cara fofa de la madre... (p. 598)

plástico:

Más de una vez la vi admirar su cuerpo en el espejo, tomarse los senos en las manos como las estatuillas sirias. (p. 24)

. . la Maga que se dibujaba frente a él como un Henry Moore en la oscuridad, una giganta vista desde el suelo, primero las rodillas a punto de romper la masa negra de la falda, después un torso que subía hacia el cielo raso, por encima una masa de pelo todavía más negro que la oscuridad... (p. I87)

de caracterización:

(Después de una admonición de Talita a la Cuca)

el encuentro de las miradas de Traveler y Oliveira fue como si dos pájaros chocaran en pleno vuelo y cayeran enredados en la casilla nueve. (p. 403)

...mientras habla esconde las manos en los bolsillos del delantal como hacen algunos animales malignos. (P. 22I)

Etienne, seguro de sí mismo como un perro o un buzón... (p. 39)

- poético:

... nos besamos como si tuviéramos la boca llena de flores o de peces, de movimientos vivos, de fragancia oscura... Y hay una sola saliva y un solo sabor a fruta madura, y yo te siento temblar contra mí como una luna en el agua. (p. 48)

Esas cosas no suceden de golpe, Pola fue viniendo como el sol en la ventana... Entraba de a poco, quitándome la sombra, y Horacio se iba quemando como en la cubierta del barco, se tostaba, era $\tan$ feliz. (p. I64)

Allí donde esté tiene el pelo ardiendo como una torre y me quema desde lejos, me hace pedazos nada más que con sui, ausencia. (p. 225). 
...vos temblabas, pura y libre como una llama..., como un río de mercurio, como el primer canto de un... pájaro cuando rompe el alba. (p. 232)

\section{El aforismo}

Se encuentran varios aforismos en la novela, algunos memorables por resumir temas principales de la obra:

La explicación es un error bien vestido. (p. 329)

Estar vivo parece siempre el precio de algo. (p.394)

... toda locura es un sueño que se fija. Sabiduría del pueblo: 'Es un pobre loco, un soñador...' (p. $45^{6}$ )

Escribir es dibujar mi mandala y a la vez recorrerlo, inventar la purificación purificándose; tarea de pobre shamán blanco con calzoncillos de nylon. (p. 458)

\section{La aposición}

La aposición, tal como la utiliza Cortázar, puede tener una forma simple:

...la muerte, ese fósforo que se apaga,... (p. 189)

el "alma" (mi yo-no-uñas) (p. 455).

- puede derivarse de una conversación indirecta, como ésta que describe un intervalo breve antes de entrar en una casa:

En el portal de la casa de Ronald hubo un interludio de cierraparaguas comment ça va a ver si alguien enciende un fósforo está rota la minuterie qué noche inmunda ah oui c'est vache... (p. 54)

A veces tiene la forma de una libre asociación de ideas:

(Babs, pensando en el blues de Bessie Smith)

...la mañana siguiente, los zapatos en los charcos, el alquiler sin 
pagar, el miedo a la vejez, imagen cenicienta del amanecer en el espejo a los pies de la cama, los blues, el cafard infinito de la vida. (p. 64)

o es más complejo, con dos sustantivos juntos y la sinestesia al final:

Tan triste oyendo al cínico Horacio que quiere un amor pasaporte, amor pasamontañas, amor llave, amor revólver, amor que le dé los mil ojos de Argos, la ubicuidad, el silencio desde donde la música es posible, la raíz desde donde se podría empezar a tejer una lengua. (p. 483 )

En la carta de la Maga, la aposición da un tono patético:

...te quiero tanto, Rocamadour, bebé Rocamadour, dientecito de ajo, te quiero tanto, nariz de azúcar, arbolito, caballito de juguete. (p. 224)

Y en el capítulo 104, las aposiciones forman todo el capitulo, después del símil inicial:

La vida, un ballet sobre un tema histórico, una historia sobre un hecho vivido, un hecho vivido sobre un hechọ real.

La vida, fotografía del númeno, posesión en las tinieblas (¿mujer, monstruo?), la vida, proxeneta de la muerte, espléndida baraja, tarot de claves olvidadas que unas manos gotosas rebajan a un triste solitario.

\section{La yuxtaposición (la enumeración)}

En alguna ocasión Oliveira le dijo a la Pola: "-Enumetá, enumerá. Eso ayuda. Sujetate a los nombres, así no te caés". (p. 422) En la novela el autor usa las enumeraciones como recurso poético, de renovación del lenguaje y de definición. Hay capítulos enteros que apenas son más que largas enumeraciones; por ejemplo la descripción borgeana de Oliveira del primer capítulo, en el que éste trata de recordar "lo insignificante, lo inostentoso, lo perecido" de su pasado (pp. Ig-20), o los capítulos I 29 y I33, en los que se examina la obra de Ceferino Piriz, La Luz de la Paz del Mundo: capítulos que forman un pastiche excelente y que son, en realidad, una enorme metáfora por medio de la enumeración. 
Cierta palabra puede llegar a tener una fuerza más universal cuando se la traduce a varias lenguas, presentando así una serie de sinónimos que restauran a la palabra su vitalidad original. Este uso puede servir de definición:

Kibbutz; colonia, settlement, asentamiento, rincón elegido donde alzar la tienda final, donde salir al aire de la noche con la cara lavada por el tiempo, y unirse al mundo, a la Gran Locura, a la Inmensa Burrada, abrirse a la cristalización del deseo, al encuentro. (p. 239)

o puede tener valor poético:

...y los gatos, siempre inevitablemente los minouche morrongos miaumiau kitten kat chat cat gatto grises y blancos y negros y de albañal, dueños del tiempo y de las baldosas tibias... (pp. 37-38)

o gran fuerza emotiva:

Sí, en el instante de la animalidad más agachada, más cerca de la excreción y sus aparatos indescriptibles, ahí se dibujan las figuras iniciales y finales... todo se resume alfa y omega, coquille, cunt, concha, con, coño, milenio, Armagedón, terramicina... (pp. 6r 26r3)

A veces la enumeración se deriva de la libre asociación de ideas. Oliveira, al escuchar el Stack O'Lee Blues, piensa en lo que es el jazz, lo que significa, en una larga asociación de ideas, cuya unidad se deriva del hecho de que todo el trozo es una sola frase larga. Êl piensa en las varias clases de jazz ("su chatleston, su black bottom, su shimmy, su foxtrot, su stomp, sus blues, para admitir las clasificaciones y las etiquetas, el estilo esto y aquello, el swing, el bebop, el cool") (p. 87) y describe, en una serie de metáforas, lo que es el jazz: ". . es inevitable, es la lluvia y el pan y la sal, algo absolutamente indiferente a los ritos nacionales, a las tradiciones inviolables, al idioma y al folklore: una nube sin fronteras, un espía del aire y del agua, una forma arquetípica, algo de antes, de abajo, que reconcilia mexicanos con noruegos y rusos y españoles..." (p. 88).

Al indicar su deseo de evitar la falsa unidad de la persona, la cual no es más que "una unidad lingüística y un prematuro esclerosamiento 
del carácter", Oliveira expresa de esta manera su deseo de escapar de la sumisión a la palabra:

... el deber, lo moral, lo inmoral y lo amoral, la justicia, la caridad, lo europeo y lo americano, el día y la noche, las esposas, las novias y las amigas, el ejército y la banca, la bandera y el oro yanqui o moscovita, el arte abstracto y la batalla de Caseros pasaban a ser como dientes o pelo, algo aceptable y fatalmente incorporado, algo que no se vive ni se analiza porque es así... (p. 99).

Y se aprovecha de la enumeración para expresar la imposibilidad de comunicar con Traveler, en una asociación interesante de palabras:

Si empezaba a tirar del ovillo iba a salir una hebra de lana, metros de lana, lanada, lanagnórisis, lanatúrner, lannapurna, lanatomía, lanata, lanatalidad, lanacionalidad, lanaturalidad, la lana hasta lanáusea pero nunca el ovillo... (p. 358).

\section{La sinestesia}

Hay varios ejemplos de sinestesia en la obra. Cuando la Maga oye palabras que no entiende, las ve como colores:

... ya Gregorovius hablaba de la inutilidad de una ontología empírica y de golpe era un Friedländer, un delicado Villon que reticulaba la penumbra y la hacía vibrar, ontología empirica, azules como de humo, rosas, empirica, un amarillo pálido, un hueco donde temblaban chispas blanquecinas. (p. I59).

Gregorio dice que París es una enorme metáfora, y la Maga dice que era "como uno de esos signos dé Sugai, con mucho rojo y negro". (p. I60) Siempre que se da cuenta de sus limitaciones intelectuales, la Maga tiene una "sensación violeta" y piensa que "Es tan violeta ser ignorante". (p. I57)

La sinestesia entra en varias descripciones:

Wong y Gregorovius se detuvieron bajo el farol (y parecían estar tomando una ducha juntos)... (pp. 53-54)

... la luz de ceniza y olivo... (p. I5) 
... un zumbido que parecía azul en la penumba del pasillo. (p. 370) ... un zumbido azul. (p. 370)

Y también aparece en varios trozos líricos:

... oír el fragor de la luna apoyando contra su oreja la palma de una pequeña mano... (p. 446)

... los senos cantan de otro modo, la boca besa más profundamente o como de lejos ... (p. 480$)$

\section{El signo antitético}

Se utiliza el signo antitético en dos formas: el contraste de dos palabras de sentido opuesto:

... la mamá patria (p. 266)

... un vidente ciego (p. I9)

...el miedo alegre (p. 378)

o el contraste de ideas o conceptos opuestos:

...te cansaste de no estar cansada... (p. I8)

...para verte como yo quería eta necesario empezar por cerrar los ojos... (P. I8)

(Morelli) se movía en esa misma ambigüedad, orquestando una obra cuya legítima primera audición debía ser quizá el más absoluto de los silencios. (p. 605)

\section{La parodia}

Es interesante notar que la parodia más humoristica de la novela - la del diálogó entre españoles-llega a tener valor metafórico cuando la misma situación se repite en la conversación entre Oliveira, Talita y Gekrepten (pp. 295-298) en la que se observa que el autor trata de mostrar la banalidad de Gekrepten. Se establece una equivalencia entre lo literario y lo vital, y éste parodia a aquél. 
Más obvias son las parodias de famosas citas literarias, como

En el principio fue la cópula, violar es explicar pero no siempre viceversa. (P. 5I)

Pinto, ergo soy. (p. 5I)

La frase gastadda (el clisé)

Para atacar el clisé, Cortázar se aprovecha de dos técnicas: o escribir el clisé como una sola palabra

La noticia corriócomounreguerodepólvora (p. 492)

Babs lo miraba admirada y bebiéndosuspalabrasdeunsolotrago. ) p. 506).

...diospatriayhogar (p. 358)

o escribirlo usando guiones para indicar una frase tan gastada que las palabras individuales ya no tienen valor:

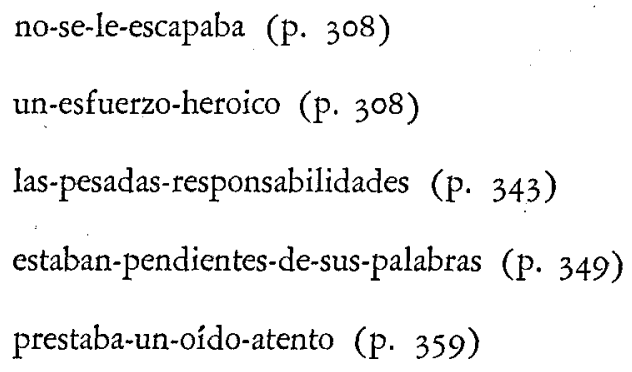

La imagen tiene una importancia especial cuando el autor escribe sobre ciertos temas. La última parte de este estudio se dedica a un comentario sobre algunos de estos temas y el uso de la imagen que hace Cortázar al desarrollarlos. 


\section{El tiempo y la Maga}

Oliveira busca la vida profunda, no en el pasado ni en el porvenir, sino adentrándose en el momento actual y exponiéndose a todos los riesgos y los deleites de la vida cotidiana. Para llegar a la vida de la Maga, él tiene que rechazar todo orden falso y evitar dar expresión verbal a sus sentimientos o analizarlos por la palabra. Nunca logra hacerlo, aunque se da cuenta de que la Maga está en la vida que él busca. Hay varias referencias al tiempo cuando los dos analizan sus relaciones. Al comienzo de la novela, Oliveira dice:

...Oh, Maga, en cada mujer parecida a vos se agolpaba como un silencio ensordecedor, una pausa filosa y cristalina que acababa por derrumbarse tristemente, como un paraguas mojado que se cierra. (pp. I5-16)

Un poco después añade:

... fuiste siempre un espejo terrible, una espantosa máquina de repeticiones... y el tiempo soplaba contra nuestras caras una lenta lluvia de renuncias y despedidas y tickets de metro. (P. I7)

A Oliveira le parece que el recuerdo (el pasado) mata al presente:

Cada vez iré sintiendo menos y recordando más, pero qué es el recuerdo sino el idioma de los sentimientos, un diccionario de caras y días y perfumes que vuelven como los verbos y los adjetivos en el discurso... (P. II5)

Durante el acto sexual, el tiempo alcanza su máxima inmediación: la Maga, en tales momentos parece ser

mítica y atroz como una estatua rodando por una montaña, arrancando el tiempo con las uñas, entre hipos y un ronquido quejumbroso que dura interminablemente. (p. 43)

La Maga describe su mundo sin dirección, caótico, cuando dice que el tiempo "es un bicho que anda y anda". (p. 22r)

Se notará en las imágenes de Oliveira su pesimismo, su incapacidad para abismarse en el momento presente sin analizarlo. Sólo durante la 
cópula (única comunión posible entre individuos) tiene el tiempo una vitalidad no analizada.

\section{La palabra}

La idea de matar la palabra para después volver a crearla es un tema repetido con frecuencia. Etienne dice que Morelli queria depegarse de las palabras, que sentía que "el lenguaje que usamos nos traiciona". (p. 503) Oliveira también se siente traicionado por las palabras, divorciado de ellas:

Hace rato que no me acuesto con las palabras. Las sigo usando, como vos y como todos, pero las cepillo muchísimo antes de ponérmelas. (p. II5)

El uso metafórico de "acostarse" no es fortuito si nos acordamos del significado que tiene el acto sexual para Oliveira.

Oliveira reserva sus metáforas más agrias para describir su lucha con las palabras, como se puede notar en este trozo:

Pero estoy solo en mi pieza, caigo en artilugios de escriba, las perras negras se vengan como pueden, me mordisquean desde abajo de la mesa. ¿Se dice abajo o debajo? Lo mismo te muerden. ¿Por qué, por qué, pourquoi, why, warum, perchè este horror a las perras negras? Miralas ahí en ese poema de Nashe, convertidas en abejas. Y ahí en dos versos de Octavio Paz, muslos del sol, recintos del verano... Tengo miedo de ese proxenetismo, de tinta y de voces, mar de lenguas lamiendo el culo del mundo. (p. 484)

Y un poco más tarde continúa:

En guerra con la palabra, en guerra, todo lo que sea necesario aunque haya que renunciar a la inteligencia, quedarse en el mero pedido de papas fritas y los telegramas Reuter, en las cartas de mi noble hermano y los diálogos del cine. Curioso, muy curioso que Puttenham sintiera las palabras como si fueran objetos, $y$ hasta criaturas con vida propia. También a mí, a veces, me parece estar engendrando ríos de hormigas feroces que se comerán el mundo. (p. 485)

Oliveira ataca a la palabra por las enumeraciones y por el "hachismo". 
Otra manera de atacarlas nos la presenta el autor en el capítulo 68, donde sustituye palabras inventadas por él, palabras que en realidad no existen, en un párrafo que describe una escena sexual. A pesar del número de sustituciones, entendemos perfectamente el sentido del capítulo. Así Cortázar nos indica que la parcial destucción de las palabras no impide la comunicación.

\section{Paris y Buenos Aires}

En la novela hay pocas descripciones de la capital argentina, pero quiero citar una que merece ser incluida por sus imágenes gráficas:

No sentís como nosotros a la ciudad como una enorme panza que oscila lentamente bajo el cielo, una araña enormísima con las patas en San Vicente, en Burzaco, en Sarandí, en el Palomar, y las otras metidas en el agua, pobre bestia, con lo sucio que es este rio. ( $p$. 269)

De París hay muchas descripciones y las imágenes son, tal vez, las mejores de la novela. Gregorovius y Oliveira describieron a París como "una enorme metáfora" (PP. I59 y 2I5) y como escenario ( $y$ en cierto sentido, meta) de la búsqueda de Horacio. Al revisar las imágenes referentes a la ciudad, me di cuenta de que forman un poema en prosa, con una gran variedad de metáforas, y decidí poner las citas aquí, sin comentario, sin observar el orden en que aparecen en la novela, siguiendo una técnica parecida a la que sugiere el autor para leer los capítulos de su obra.

. . el frio entra por una suela rota, en la ventana de ese hotel una cara como de payaso hace muecas detrás del vidrio. La sombra de una paloma roza un excremento de perro: París. (p. 540)

París debía ser una enorme brubuja grisácea en la que poco a poco se levantaría el alba. (p. 204)

París, una tarjeta postal con un dibujo de Klee al lado de un espejo sucio. (p. 24)

...un gran amor a ciegas, todos estamos perdidamente enamorados pero hay algo verde, una especie de musgo, qué sé yo. (p. I63) 
París es un centro, entendés, una mandala que hay que recorrer sin dialéctica, un laberinto donde las fórmulas pragmáticas no sirven más que para perderse. (p. 485)

...tendí la mano y toqué el ovillo París, su materia infinita arrollándose a sí misma, el magma del aire y de lo que se dibujaba en la ventana, nubes y buhardillas; entonces no había desorden, entonces el mundo seguía siendo algo petrificado y establecido, un juego de elementos girando en sus goznes, una madeja de calles y árboles $y$ nombres y meses (p. 26)

...París nos destruye despacio, deliciosamente, triturándonos entre flores viejas y manteles de papel con manchas de vino, con su fuego sin color que corre al anochecer saliendo de los portales carcomidos. Nos arde un fuego inventado, una incandescentetura, un artilugio de la raza, una ciudad que es el Gran Tornillo, la horrible aguja con su ojo nocturno por donde corre el hilo del Sena, máquina de torturas como puntillas, agonía en una jaula atestada de golondrinas enfurecidas. (pp. 439-440)

\section{La buisqueda de Oliveira}

Todo en esta antinovela es símbolo, empezando con el título mismo, Rayuela, metáfora por la búsqueda de Oliveira. Oliveira describe los ingredientes que son necesarios para jugar a la rayuela: "una acera, una piedrita, un zapato, y un bello dibujo con tiza, preferentemente de colores". (p. 25I) La piedrita parece representar la cruz - "llegar con la piedrita (¿cargar con su cruz?...) -, símbolo de sufrimiento y peligto. El zapato representa el esfuerzo, la lucha por llegar al Cielo. (p. 252) El Cielo, azul, es "un nombre infantil de su kibbutz..." (p. 252) La imagen de la rayuela, con sus varias metáforas componentes, se repite en diversas partes de la novela. En el manicomio, Oliveira ve a Talita que juega a la rayuela, y cree que es la Maga. (p. 366) Oliveira mismo imita las acciones de un jugador de rayuela: "Hizo una cosa tonta: encogiendo la pierna izquierda, avanzó a pequeños saltos por el pasillo... A cada salto había repetido entre dientes el nombre de Manú". (p. 367) El habla de como Talita había jugado a la rayuela:

Perdiste en la tercera casilla. A la Maga le hubiera pasado lo mismo, es incapaz de perseverar, no tiene el menor sentido de las distancias, 
el tiempo se le hace trizas en las manos, anda a tropezones con el mundo. (p. 369)

Para Oliveira, el besar a Talita es

como la caricia a la paloma, como la idea de levantarse para hacerle una limonada a un guardián, como doblar una pierna y empujar un tejo de la primera a la segunda casilla, de la segunda a la tercera. De alguna manera habían ingresado en otra cosa, en ese algo donde se podía estar de gris y ser de rosa, donde se podía haber muerto ahogada en un río (y eso ya no lo estaba pensando ella) y asomar en una noche de Buenos Aires para repetir en la rayuela la imagen misma de lo que acababan de alcanzar, la última casilla, el centro del mandala, el Ygdrassil vertiginoso por donde se salía a una playa abierta, a una extensión sin límites, al mundo debajo de los párpados que los ojos vueltos hacia adentro reconocían y acataban. (pp. 373-374)

Así el juego refleja - anticipa - las acciones de los personajes, y especialmente las de Oliveira. Todos entran en el juego, pero sólo Oliveira logra pasar todas las casillas hasta llegar al Cielo.

La búsqueda es el proceso por el que Oliveira pasa de casilla en casilla, camino al Cielo. Ya desde el comienzo de la novela lo encontramos buscando algo:

Ya para entonces me había dado cuenta de que buscar era mi signo, emblema de los que salen de noche sin propósito fijo, razón de los matadores de brújulas. (p. 20)

En medio de la confusión de la vida, él cree que la vida tiene que tener algún propósito: "No puede ser que estemos aquí para no poder ser". (p. 92) ¿Qué es lo que busca? No sólo la reconciliación con Dios, sino la fraternidad del hombre, la comunión entre la humanidad:

...especulaba sobre los tres días en que el mundo está abierto, cuando los manes ascienden y hay puente del hombre al agujero en lo alto, puente del hombre al hombre (porque, ¿quién trepa hasta el agujero si no es para querer bajar cambiado y encontrarse otra vez, pero de otra manera, con su raza?). (p. 3r3) 
Con el místico, sufre la angustia del mundo, desespera y cree que jamás dará con la unión que tanto desea. Esta unión la expresa con una serie de metáforas:

A Oliveira le iba a doler siempre no poder hacerse ni, siquiera una noción de esa unidad que otras veces llamaba centro, y que a falta de contorno más preciso se reducía a imágenes como la de un grito negro, un kibbutz del deseo, ( $\tan$ lejano ya, ese kibbutz de madrugada y vino tinto) y hasta una vida digna de ese nombre porque... había sido lo bastante infeliz como para imaginar la posibilidad de una vida digna al término de diversas indignidades minuciosamente llevadas a cabo. (p. 384)

Estas indignidades se parecen a los ritos de purificación de algunos santos o místicos. En el caso de Oliveira, él se propone deshacerse de un mundo que considera falso, por vía de la acumulación. Gregorovius describe así la reacción de Oliveira frente al mundo:

La cosidad es ese desagradable sentimiento de que allí donde termina nuestra presunción empieza nuestro castigo... Oliveira es patológicamente sensible a la imposición de lo que lo rodea, del mundo en que se vive, de lo que le ha tocado en suerte, para decirlo amablemente. En una palabra, le revienta la circunstancia. Más brevemente, le duele el mundo... (p. 84)

Para curarse de la cosidad, Oliveira se precipita a lo absurdo, lo cual él describe así:

Lo que no entendemos es por qué eso tiene que suceder así, por qué nosotros estamos aquí y afuera está lloviendo. Lo absurdo no son las cosas, lo absurdo es que las cosas estén ahí y las sintamos como absurdas. A mí se me escapa la relación que hay entre yo y esto que me está pasando en este momento. No te niego que me esté pasando. Vaya si me pasa. $\mathrm{Y}$ eso es lo absurdo. (pp. I94-I95)

Para él, la historia, el folklore, las costumbres, las reglas, los hábitos - todo lo que impone orden al hombre o una actitud artificial- le parece absurdo y sin sentido. La idea de su desapego de un mundo absurdo se reșume en los siguientes şimileș: 
A veces me convenzo de que la estupidez se llama triángulo, de que ocho por ocho es la locura o un perro. Abrazado a la Maga, esa concreción de nebulosa, pienso que tanto sentido tiene hacer un muñequito con miga de pan como escribir la novela que nunca escribiré o defender con la vida las ideas que redimen a los pueblos. (p. 28)

Sólo en ciertos momentos de crisis, de irracionalidad, puede escaparse del mundo:

$Y$ esas crisis que la mayoría de la gente considera como escandalosas, como absurdas, yo personalmente tengo la impresión de que sirven para mostrar el verdadero absurdo, el mundo ordenado y en calma... Los milagros nunca me han parecido absurdos; lo absurdo es lo que los precede y los sigue. (p. 196)

El esfuerzo del místico para librarse del mundo es un esfuerzo solitario: no puede ser compartido, le separa de los demás. Es lo mismo en el caso de Oliveira. No hay contacto verdadero, profundo, con ningún otro ser.

Los contactos en la acción y la raza y el oficio y la cama y la cancha, eran contactos de ramas y hojas que se entrecruzan y acarician de árbol a árbol, mientras los troncos alzan desdeñosos sus paralelas inconciliables. (P. I20)

Cuando trata de ayudar a Berthe Trépat, el fracaso es inevitable. Lo que comenzó como un sentimiento de lástima, terminó con las más agrias descripciones de la vieja pianista ("esa cara de muñeca rellena de estopa" (p. I 29), "esa muñeca desteñida", "ese pobre globo inflado donde la estupidez y la locura bailaban la verdadera pavana de la noche" (p. I36), "esa bola encorsetada que se movía como un erizo bajo la lluvia y el viento" (p. I4I). Aún sus relaciones con la Maga no tienen significado profundo para él:

...vamos componiendo una figura absurda, ... dibujamos con nuestros movimientos una figura idéntica a la que dibujan las moscas cuando vuelan en una pieza, de aquí para allá, bruscamente dan media vuelta, de allá para aquí, eso es lo que se llama movimiento brownoideo. . . todo eşo va tejiendo un dibujo, una figura, algo in- 
existente como vos y como yo,... una interminable figura sin sentido. (p. 233)

Esto lo ha sentido la Maga y lo expresa con estas imágenes:

... sos el que va al museo y mira los cuadros. Quiero decir que los cuadros están ahí y vos en el museo, cerca y lejos al mismo tiempo. Yo soy un cuadro, Rocamadour es un cuadro. Etienne es un cuadro, esta pieza es un cuadro. Vos creés que estás en esta pieza pero no estás. Vos estás mirando la pieza, no estás en la pieza. (p. 34).

$Y$ hay cierta alienación de sí mismo, como se revela en esta frase dirigida a Traveler (el cual, en ciertos aspectos, parece ser un Oliveira "histórico"):

...siento que sos mi doppelgänger, porque todo el tiempo estoy yendo y viniendo de tu territorio al mío, si es que llego al mío, y en esos pasajes lastimosos me parece que vos sos mi forma que se queda ahí mirándome con lástima, sos los cinco mil años de hombre amontonados en un metro setenta... (p. 400)

En alguna ocasión Etienne se aprovechó de una frase de estilo barroco para describir la angustia de Oliveira: dijo que éste era "El alacrán clavándose el aguijón, harto de ser un alacrán pero necesitado de alacranidad para acabar con el alacrán". (pp. I89-I90) Por lo cual él queria decir que Oliveira había revelado una "inexplicable tentación de suicidio de la inteligencia por vía de la inteligencia misma" (p. I89). Sería difícil ofrecer mejor descripción de la meta del místico de la Edad Media. Asi el "suicidio" de Oliveira, sea físico o metafórico, representa su escape de un mundo que no puede tolerar y su llegada al Cielo de la rayuela, la reconciliación mística entre hombre y Dios y entre hombre y hombre.

\section{JOHN G. COPELAND}

